\title{
MANEJO DE IRRIGAÇÃO E TEORES DE NITROGÊNIO, FÓSFORO E BORO NA CULTURA DO FEIJÃO
}

\author{
Adriano da Silva Lopes ${ }^{1 *}$, Eder Duarte Fanaya Júnior ${ }^{2}$, Luan Eudes da Silva ${ }^{3}$, Danilo \\ Prevedel Capristo ${ }^{4}$, Douglas Coimbra da Silva ${ }^{4}$
}

\begin{abstract}
${ }^{1}$ Prof. Adjunto. Programa de Pós-graduação em Agronomia - Área de concentração em Produção vegetal Unidade Universitária de Aquidauana. Universidade Estadual de Mato Grosso do Sul, UEMS, Aquidauana, Mato Grosso do Sul, Brasil.

${ }^{2}$ Doutorando em Engenharia de Sistemas Agrícolas - Departamento de Engenharia de Biossistemas. Escola Superior de Agricultura "Luiz de Queiroz", ESALQ/USP. Piracicaba, São Paulo, Brasil.

${ }^{3}$ Eng. Agrônomo. Unidade Universitária de Aquidauana. Universidade Estadual de Mato Grosso do Sul, UEMS, Aquidauana, Mato Grosso do Sul, Brasil.

${ }^{4}$ Graduando do curso de Agronomia. Unidade Universitária de Aquidauana. Universidade Estadual de Mato Grosso do Sul, UEMS, Aquidauana, Mato Grosso do Sul, Brasil.
\end{abstract}

RESUMO: O objetivo foi verificar a influência da adubação nitrogenada de cobertura e do manejo da irrigação na cultura do feijão, irrigada por aspersão convencional, no Mato Grosso do Sul, relacionando a produtividade de grãos com teor de N, P e B foliar. O delineamento experimental foi em blocos casualizados, com parcelas subdivididas, com três manejos de irrigação nas parcelas (tanque Classe A), Hargreaves-Samani e Penman-Monteith) e três doses de adubação nitrogenada nas subparcelas $\left(0,50,100\right.$ e $\left.150 \mathrm{~kg} \mathrm{ha}^{-1} \mathrm{de} \mathrm{N}\right)$ e o tratamento controle, sem aplicação de N. Não houve diferença nos teores foliares de N, P e B em função das doses de nitrogênio, e os teores não foram influenciados pelos manejos da irrigação. As maiores produtividades não estão relacionadas com os maiores teores foliares de $\mathrm{N}, \mathrm{Pe} \mathrm{B}$. A aplicação de elevadas doses de $\mathrm{N}$ não acarretam em maiores acúmulos de $\mathrm{N}, \mathrm{P}$ e B foliar.

Palavras-chave: Adubação nitrogenada. Hargreaves-Samani. Penman-Monteith. Phaseolus vulgaris. Tanque Classe A.

\section{IRRIGATION MANAGEMENT AND LEVELS OF NITROGEN, PHOSPHORUS AND BORON IN BEAN CROP}

\begin{abstract}
The aim of this study was to investigate the influence of nitrogen fertilization and irrigation management in the bean crop, irrigated by sprinkler, in Mato Grosso do Sul state, relating grain yield with N, P and B leaf content. The experiment was conducted at the Universidade Estadual de Mato Grosso do Sul (UEMS), the bean cultivar sown pearl being used in the winter of 2011. Experimental design was a randomized complete block design with split plot, with three irrigation management the plots (Class A pan), Hargreaves-Samani and Penman-Monteith) and four nitrogen fertilizer levels as subplots $(0,50,100$ and $150 \mathrm{~kg}$ $\left.\mathrm{ha}^{-1}\right)$. Foliar concentrations of nitrogen $(\mathrm{N})$, phosphorus $(\mathrm{P})$ and boron $(\mathrm{B})$ were evaluate, where the results for irrigation were compared by mean test, being used the Tukey test at $5 \%$ probability, and for nitrogen fertilization, regression analyzes were perform. It appears that
\end{abstract}


there is no significant difference in foliar concentrations of $\mathrm{N}, \mathrm{P}$ and $\mathrm{B}$ as a function of nitrogen and it did not influenced by irrigation management. It is conclude that the greatest yields are not relate to the major foliar $\mathrm{N}, \mathrm{P}$ and $\mathrm{B}$. The application of high doses of $\mathrm{N}$ not carrying with higher accumulation of $\mathrm{N}, \mathrm{P}$ and $\mathrm{B}$ leaf.

Key words: Nitrogen rates. Hargreaves-Samani. Penman-Monteith, Phaseolus vulgaris. Class A pan.

\section{INTRODUÇÃO}

A cultura do feijão (Phaseolus vulgaris) é uma das principais fontes de proteína da dieta alimentar dos brasileiros, principalmente, para as populações de baixa renda. Além disso, muitos pequenos produtores estão envolvidos na sua produção (PELEGRIN et al., 2009).

No Brasil é uma das culturas importantes, sendo a quinta mais produzida, com aproximadamente $9 \%$ da área agricultável do país, conferindo o título de maior produtor mundial desta leguminosa, com uma estimativa de 3,107 milhões de toneladas de grãos colhidas na safra 2016/17 (CONAB, 2016).

A tecnologia rudimentar utilizada e as variações climáticas, principalmente o regime hídrico, são as principais causas de baixas produtividades na maioria das regiões produtoras (PAVANI et al., 2009).

Esta cultura era cultivada apenas no verão, contudo, surgiu o cultivo de sequeiro e, mediante a novas tecnologias e avanços na pesquisa, surgiu a alternativa de cultivá-lo no inverno, designado "feijão de inverno" ou "feijão irrigado", sendo a irrigação a ferramenta essencial para suprir a deficiência hídrica ocasionada nesta época do ano (LOPES et al., 2011).

Em função de possuir sistema radicular superficial e um ciclo curto, o feijoeiro é uma planta exigente em nutrientes (CUNHA et al., 2011). Segundo Pacheco et al. (2012), em culturas irrigadas, a nutrição é um fator que se deve considerar para o bom desenvolvimento das mesmas, expressando seu máximo potencial produtivo quando realizada adequadamente.

A adubação com macronutrientes, como nitrogênio e fósforo, objetiva-se aumentar a produtividade agrícola (PROCÓPIO et al., 2005). Não obstante, micronutrientes como o boro são essenciais para o desenvolvimento normal de culturas anuais, além de que sua deficiência provoca grandes perdas de produtividade.

Com isso, o objetivo foi verificar a influência da adubação nitrogenada em cobertura e do manejo da irrigação na cultura do feijão irrigado por aspersão convencional, em Aquidauana - MS, relacionando a produtividade de grãos aos teores de N, P e B foliar. 


\section{MATERIAL E MÉTODOS}

O experimento foi conduzido na área experimental de agricultura irrigada da Universidade Estadual de Mato Grosso do Sul (UEMS), Unidade Universitária de Aquidauana, MS, com coordenadas geográficas $20^{\circ} 20^{\prime} \mathrm{S}, 55^{\circ} 48^{\prime} \mathrm{O}$ e altitude média de 191 metros. O clima da região é tropical quente sub-úmido, que segundo a classificação de Köppen, é do tipo Aw, com precipitação pluviométrica média anual de $1200 \mathrm{~mm}$. O solo da área foi identificado como Argissolo Vermelho distrófico (SCHIAVO et al., 2010).

A cultura do feijão foi instalada dia 26 de maio de 2011 (feijão de inverno) e conduzida no sistema plantio direto. Foi utilizada a cultivar Pérola IAPAR 81, cujas sementes foram tratadas no dia anterior à semeadura, sendo adotado o espaçamento de $0,45 \mathrm{~m}$ e 16 sementes por metro, com a emergência ocorrendo 9 dias após a semeadura.

As irrigações e adubação de cobertura foram realizadas de acordo com os tratamentos empregados. A colheita das parcelas foi realizada, manualmente, aos 84 dias após a emergência.

O experimento foi conduzido sob sistema de irrigação por aspersão convencional, com vazão unitária dos aspersores de $2,87 \mathrm{~m}^{3} \mathrm{~h}^{-1}$ e pressão de serviço de $30 \mathrm{~m}$ c.a., instalados a 1 $\mathrm{m}$ do solo e espaçados a $12 \mathrm{~m}$ entre si.

Para a aplicação da adubação de semeadura, utilizou-se $16 \mathrm{~kg} \mathrm{ha}^{-1}$ de nitrogênio (N), em todas as parcelas e, em cobertura (aos 30 dias após a emergência - estádio fenológico $\mathrm{V}_{4}$ ), foram aplicadas as doses em função dos tratamentos. Foi utilizado como fonte de $\mathrm{N}$ a uréia e, após sua aplicação, houve a aplicação de $8 \mathrm{~mm}$ de água via irrigação para incorporação do adubo.

A adubação potássica e fosfatada foi realizada a partir da análise química do solo (Tabela 1) e de acordo com Ambrosano et al. (1996), sendo utilizado $200 \mathrm{~kg} \mathrm{ha}^{-1}$ da fórmula 08-16-16, na semeadura.

Tabela 1. Análise química do solo na área do feijoeiro irrigado.

\begin{tabular}{|c|c|c|c|c|c|c|c|c|c|c|c|}
\hline Camada & & $P$ & $\mathrm{M} \mathrm{O}$ & Teytura & $\mathrm{K}$ & $\mathrm{Ca}$ & $\mathrm{Mg}$ & $\mathrm{Al}$ & $\mathrm{H}+\mathrm{Al}$ & SB & $\mathrm{T}$ \\
\hline $\mathrm{m}$ & pп & $\mathrm{mg} \mathrm{dm^{-3 }}$ & $\mathrm{g} \mathrm{dm}^{-3}$ & rextura & \multicolumn{7}{|c|}{$\mathrm{cmol}_{\mathrm{c}} \mathrm{dm}^{-3}$} \\
\hline $0,0-0,2$ & 5,8 & 52,7 & 23 & $3 * *$ & 1,02 & 2,7 & 0,8 & 0,0 & 2,4 & 4,52 & 6,92 \\
\hline
\end{tabular}

O delineamento experimental utilizado foi o de blocos casualizados, com parcelas subdivididas, composto por três blocos e duas replicações dentro de cada bloco (BANZATTO; KRONKA, 1989).

A área abrangida pela irrigação em cada bloco correspondeu a $108 \mathrm{~m}$ de comprimento por $24 \mathrm{~m}$ de largura, respeitando uma distância de $12 \mathrm{~m}$ de bordadura entre os mesmos e também entre os tratamentos de manejo de irrigação. Cada unidade experimental correspondeu a 5 linhas de plantas com $5 \mathrm{~m}$ de comprimento, totalizando $11,25 \mathrm{~m}^{2}$. 
Os tratamentos empregados, nas parcelas, corresponderam a três manejos de irrigação: Manejo de irrigação com a utilização do tanque Classe A (TCA); Manejo de irrigação com Penman-Monteith (PM); Manejo de irrigação pelo método de Hargreaves-Samani (HS) e, nas subparcelas, quatro níveis de adubação nitrogenada em cobertura: sem aplicação de adubação nitrogenada em cobertura (N-0); aplicação de $50 \mathrm{~kg} \mathrm{ha}^{-1}$ de adubação nitrogenada em cobertura (N-50); aplicação de $100 \mathrm{~kg} \mathrm{ha}^{-1}$ de adubação nitrogenada em cobertura (N-100); aplicação de $150 \mathrm{~kg} \mathrm{ha}^{-1}$ de adubação nitrogenada em cobertura (N-150).

Para o manejo de irrigação, utilizou-se fator p de depleção de água no solo de 0,5 (ALLEN et al., 1998) e, a estimativa da evapotranspiração da cultura (ETc) foi realizada conforme equação 01:

$\mathrm{ETc}=\mathrm{ETokc}$

Em que: ETc - evapotranspiração da cultura $\left(\mathrm{mm} \mathrm{d}^{-1}\right)$; ETo - evapotranspiração de referência $\left(\mathrm{mm} \mathrm{d}^{-1}\right) ; \mathrm{kc}$ - coeficiente da cultura (adimensional), onde foram utilizados valores de 0,25 para fase inicial e desenvolvimento vegetativo; 1,15 para fase de floração e enchimento de grãos; e 0,35 para a fase de maturação (ALLEN et al., 1998).

A ETo foi obtida em função dos tratamentos empregados. Para o manejo da irrigação TCA, segundo Allen et al. (1998), utilizou-se a equação 2:

$\mathrm{ETo}_{(\mathrm{TCA})}=\mathrm{ECA} \mathrm{kp}$

Em que: $\mathrm{ETo}_{(\mathrm{TCA})}$ - Evapotranspiração de referência estimada pelo método do tanque Classe A $\left(\mathrm{mm} \mathrm{d}^{-1}\right)$; ECA - Evaporação do tanque Classe A $\left(\mathrm{mm} \mathrm{d}^{-1}\right) ; \mathrm{kp}$ - Coeficiente do tanque Classe A ( 0,75 , adimensional).

Na estimativa da ETo pelo o método de PM, utilizou-se a equação 3 (ALLEN et al., 1998):

$\mathrm{ETo}_{(\mathrm{PM})}=\frac{0,408 \mathrm{~s}(\mathrm{Rn}-\mathrm{G})+\gamma\left(\frac{900 \mathrm{U}_{2}}{\mathrm{~T}_{\mathrm{med}}+273}\right)(\text { es - ea })}{\mathrm{s}+\left(1+0,34 \mathrm{U}_{2}\right)}$

Em que: $\mathrm{ETo}_{(\mathrm{PM})}$ - evapotranspiração de referência estimada pelo método Penman-Monteith $\left(\mathrm{mm} \mathrm{d}^{-1}\right) ; \mathrm{s}$ - declinação da curva de saturação do vapor da água $\left(\mathrm{kPa}^{\circ} \mathrm{C}^{-1}\right) ; \mathrm{Rn}$ - saldo de radiação $\left(\mathrm{MJ} \mathrm{m}^{-2} \mathrm{~d}^{-1}\right) ; \mathrm{G}$ - fluxo de calor no solo $\left(\mathrm{MJ} \mathrm{m}^{-2} \mathrm{~d}^{-1}\right) ; \gamma$ - constante psicrométrica $\left(0,0659823 \mathrm{kPa}^{\circ} \mathrm{C}^{-1}\right) ; \mathrm{U}_{2}$ - velocidade média do vento a $2 \mathrm{~m}$ acima da superfície do solo $\left(\mathrm{m} \mathrm{s}^{-}\right.$ $\left.{ }^{1}\right)$; $\mathrm{T}_{\text {méd }}$ - temperatura média do ar $\left({ }^{\circ} \mathrm{C}\right)$; es = pressão de saturação de vapor $(\mathrm{kPa})$; ea = pressão atual de vapor $(\mathrm{kPa})$.

Para a estimativa da ETo pelo método HS, utilizou-se a equação 4 (PEREIRA et al., 1997):

$\mathrm{ETo}_{(\mathrm{HS})}=0,0135 \mathrm{kt} \mathrm{Ra}\left(\mathrm{T}_{\text {máx }}-\mathrm{T}_{\text {mín }}\right)^{0,5}\left(\mathrm{~T}_{\text {méd }}+17,8\right)$

Em que: $\operatorname{ETo}_{(\mathrm{HS})}$ - evapotranspiração de referência estimada segundo método de HargreavesSamani $\left(\mathrm{mm} \mathrm{d}^{-1}\right) ; \mathrm{Ra}=$ radiação extraterrestre $\left(\mathrm{MJ} \mathrm{m}^{-2} \mathrm{~d}^{-1}\right) ; \mathrm{T}_{\text {máx }}$ - temperatura máxima do ar

Cultura Agronômica, Ilha Solteira, v.26, n.1, p.21-32, 2017 
$\left({ }^{\circ} \mathrm{C}\right) ; \mathrm{T}_{\text {mín }}$ - temperatura mínima do ar $\left({ }^{\circ} \mathrm{C}\right)$; $\mathrm{T}_{\text {méd }}$ - temperatura média do ar $\left({ }^{\circ} \mathrm{C}\right)$; $\mathrm{kt} \mathrm{-}$ coeficiente empírico empregado em regiões continentais $(0,162)$ (adimensional).

Quando a cultura atingiu o estágio fenológico $\mathrm{R}_{6}$ foi realizada a coleta de folhas para a avaliação dos teores de nitrogênio $(\mathrm{N})$, fósforo $(\mathrm{P})$ e boro $(\mathrm{B})$, onde foram amostradas, aleatoriamente, 30 plantas de cada subparcela. De cada planta amostrada, coletou-se o terceiro trifólio completo (limbo + pecíolo), contado de cima para baixo na haste principal (AMBROSANO et al., 1996).

Após a amostragem, as folhas foram lavadas para retirada das impurezas, sendo esta constituída de três etapas: a) lavagem das folhas em solução de água + detergente a 0,001\%, b) posteriormente, em solução de água + ácido clorídrico $(\mathrm{HCl})$ a 0,005\%, c) por último, em água destilada.

Depois de lavadas, as folhas ficaram à sombra por aproximadamente 4 horas, colocadas em sacos de papel e levadas a estufa com circulação forçada de ar por 72 horas à temperatura de $65{ }^{\circ} \mathrm{C}+/-5{ }^{\circ} \mathrm{C}$. Logo após, as mesmas foram moídas e armazenadas em frascos plásticos (MALAVOLTA; LIMA FILHO, 1997). O teor de $\mathrm{N}$ foi obtido por titulação, pelo método de Kjeldahl e, o de fósforo e boro, em $\mathrm{g} \mathrm{kg}^{-1}$ e $\mathrm{mg} \mathrm{kg}^{-1}$, respectivamente, foram obtidos por espectrofotometria de chama pelas seguintes equações (EMBRAPA, 2009):

$$
\mathrm{P}_{\left(\mathrm{gkg}^{-1}\right)}=\mathrm{mg} \mathrm{L}^{-1} 0,2
$$

Onde o valor $\left(\mathrm{mg} \mathrm{L}^{-1}\right)$ foi obtido pela seguinte equação da curva de absorbância:

$y=4,6703 x+0,1874$

$$
\mathrm{B}_{\left(\mathrm{mgkg}^{-1}\right)}=\mathrm{mg} \mathrm{L}^{-1} 50
$$

Onde o valor ( $\left.\mathrm{mg} \mathrm{L}^{-1}\right)$ é obtido pelas seguintes equações da curva de absorbância:

$\mathrm{y}=8,5946 \mathrm{x}-0,8258\left(1^{\circ}\right.$ dia de análise $)$

$\mathrm{y}=10,371 \mathrm{x}-1,0494\left(2^{\circ}\right.$ dia de análise $)$

Ao final do ciclo da cultura foi determinada a produtividade e, posteriormente, relacionou-a com os teores de nutrientes foliares e influência da adubação nitrogenada de cobertura, além do manejo de irrigação.

A produtividade foi estimada por meio da pesagem dos grãos colhidos na área útil de cada parcela. Para correção da umidade, foram utilizadas três amostras aleatórias de 100 grãos, por parcela, que foram pesadas em balança de precisão de $0,01 \mathrm{~g}$, para determinação da umidade e correção do resultado para $13 \%$ em base úmida.

Os resultados para manejo de irrigação foram comparados pelo teste de médias, sendo utilizado o teste Tukey $(\mathrm{p}<0,05) \mathrm{e}$, para as doses de adubação nitrogenada, foram realizadas análises de regressão. 


\section{RESULTADOS E DISCUSSÃO}

A matriz de correlação indicou que os atributos produtividade e nitrogênio podem ser relacionados linearmente, assim como fósforo e boro (Tabela 2).

Tabela 2. Matriz de correlação entre a produtividade do feijoeiro irrigado e os teores de nutrientes foliares, cultivado no município de Aquidauana - MS.

\begin{tabular}{ccccc}
\hline & Produtividade & N & P & B \\
\hline Produtividade & 1,000 & & & \\
N & $0,398^{*}$ & 1,000 & & \\
P & $0,198^{\mathrm{NS}}$ & $-0,008^{\mathrm{NS}}$ & 1,000 & \\
$\mathrm{~B}$ & $0,190^{\mathrm{NS}}$ & $-0,092^{\mathrm{NS}}$ & $0,324^{*}$ & 1,000 \\
\hline
\end{tabular}

* - Correlação de Pearson, a 5\% de significância estatística. ${ }^{\text {NS }}$ - Correlação não significativa.

Segundo Soratto et al. (2004), maiores produtividades podem estar relacionadas com o melhor aproveitamento do $\mathrm{N}$ absorvido. Eles enfatizam que isso ocorre, possivelmente, devido a maior manutenção da quantidade de água no solo, em função da maior infiltração e menor evapotranspiração proporcionada pelo sistema plantio direto que, também, foi empregado nesse trabalho.

A relação entre B e P, segundo Prado (2008), pode ser devido a presença do B afetar a atividade de componentes específicos da membrana celular, podendo aumentar a capacidade das raízes em absorver o $\mathrm{P}$, o que, pelos resultados encontrados, pode ter ocorrido nesse experimento.

Verifica-se que não houve diferença significativa dos atributos analisados em relação aos manejos de irrigação (Tabela 3). $\mathrm{O}$ teor de $\mathrm{N}$ foliar não diferiu estatisticamente pelos manejos de irrigação adotados e os mesmos não proporcionaram aumento de produtividade. Os teores de $\mathrm{N}$ variaram de 26,2 a $26,6 \mathrm{~g} \mathrm{~kg}^{-1}$, ficando abaixo do nível crítico para a cultura do feijoeiro que, segundo a Embrapa (2009), é de $30 \mathrm{~g} \mathrm{~kg}^{-1}$.

Tabela 3. Teores de nutrientes foliares e produtividade de grãos entre os manejos de irrigação.

\begin{tabular}{cllcc}
\hline \multirow{2}{*}{ MANEJO } & \multicolumn{1}{c}{$\mathrm{N}$} & $\mathrm{P}$ & $\mathrm{B}$ & Produtividade \\
\cline { 2 - 5 }$\left(\mathrm{g} \mathrm{kg}^{-1}\right)$ & \multicolumn{2}{c}{$\left(\mathrm{m} \mathrm{kg}^{-1}\right)$} & $\left(\mathrm{kg} \mathrm{ha}^{-1}\right)$ \\
\hline TCA & $26,285 \mathrm{a}$ & $3,433 \mathrm{a}$ & $33,551 \mathrm{a}$ & $1.372 \mathrm{a}$ \\
$\mathrm{HS}$ & $26,174 \mathrm{a}$ & $3,387 \mathrm{a}$ & $31,076 \mathrm{a}$ & $1.197 \mathrm{a}$ \\
PM & $26,571 \mathrm{a}$ & $3,437 \mathrm{a}$ & $33,366 \mathrm{a}$ & $1.099 \mathrm{a}$ \\
\hline CV $(\%)$ & 24,7 & 18,0 & 22,0 & 35,4 \\
\hline
\end{tabular}

$\overline{\mathrm{CV}}=$ Coeficiente de Variação; Médias seguidas de letras iguais, na coluna, não diferem entre si pelo teste de Tukey ( $p>0,05)$.

Os valores de $\mathrm{P}$ foliar encontrados ficaram em torno de $3,4 \mathrm{~g} \mathrm{~kg}^{-1}$, corroborando com a faixa adequada para o feijoeiro que varia de 2,5 a $4,0 \mathrm{~g} \mathrm{~kg}^{-1}$. Verifica-se que os teores de $\mathrm{B}$ tiveram uma variação de 31,1 a $33,6 \mathrm{mg} \mathrm{kg}^{-1}$, sendo superior a faixa adequada para o feijoeiro, que é de 15 a $26 \mathrm{mg} \mathrm{kg}^{-1}$ (EMBRAPA, 2009). Silva et al. (2010) encontraram teores de B

Cultura Agronômica, Ilha Solteira, v.26, n.1, p.21-32, 2017 
ainda mais elevados $\left(61,8 \mathrm{mg} \mathrm{kg}^{-1}\right)$ na cultura do feijoeiro em Botucatu, SP.

Devido ao B estar diretamente ligado ao crescimento meristemático (ARAÚJO; CAMACHO, 2012), provavelmente o alto teor do nutriente se deve ao fato da cultura estar no final do estádio vegetativo na época de amostragem, coincidindo com o período de maior absorção do B.

Pode-se observar pelas Figuras 1A, 1B e 1C que não houve um comportamento definido, sendo contrário aos resultados encontrados por Crusciol et al. (2007), onde os autores observaram que a adubação nitrogenada de cobertura proporcionou aumento linear no teor de $\mathrm{N}$ nas folhas do feijoeiro cultivado em sucessão a gramíneas no sistema plantio direto.
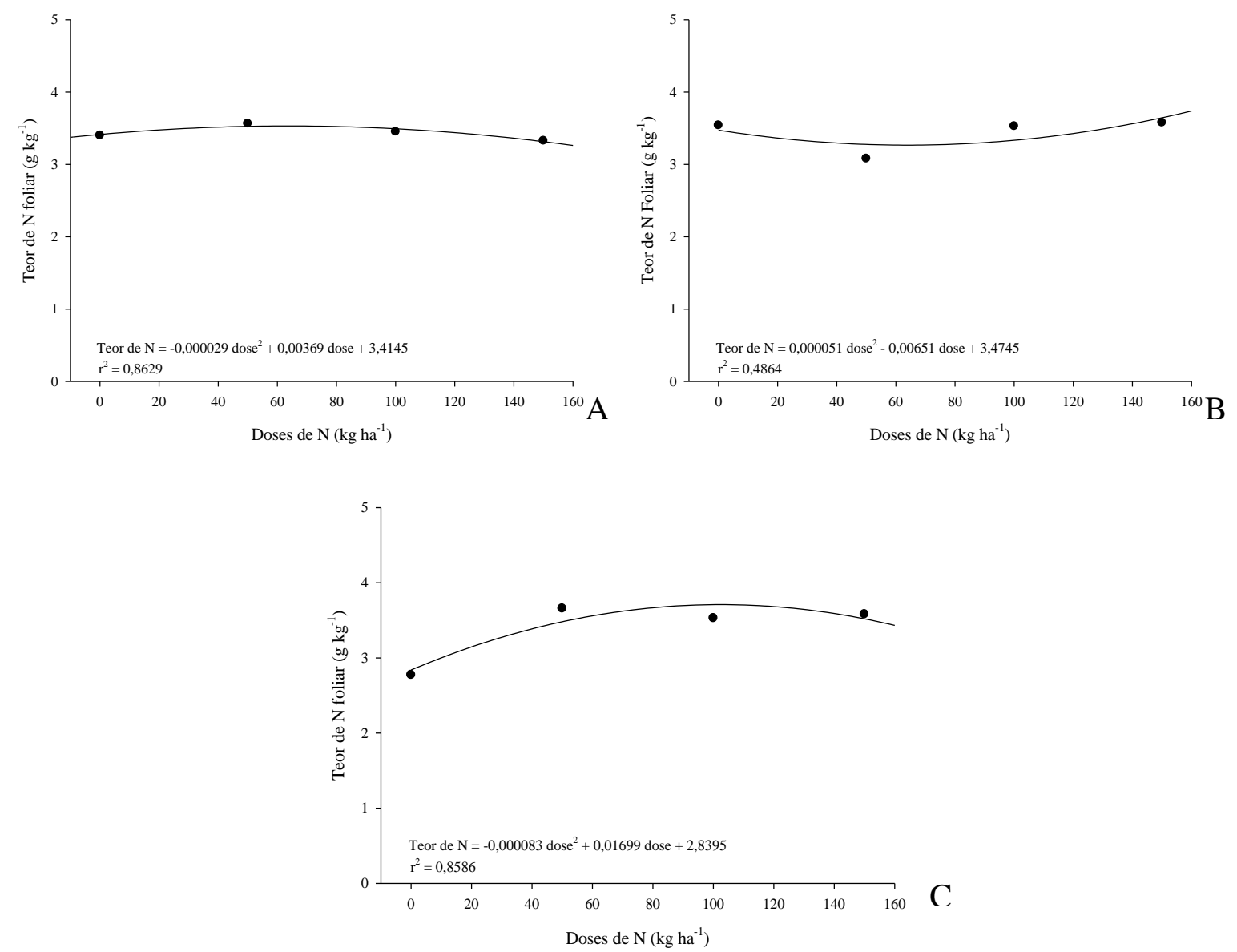

Figura 1. Teor de $\mathrm{N}$ foliar em diferentes doses de $\mathrm{N}$ na cultura do feijoeiro irrigado em sistema de plantio direto com os manejos de irrigação: Tanque Classe A (A), HargreavesSamani (B) e Penman-Monteith (C), em Aquidauana - MS.

Segundo Arf et al. (2011), o que pode ter ocorrido é uma maior competição intraespecífica pelo nutriente, causado pela alta população de plantas, o que gera menor absorção de $\mathrm{N}$, acarretando em menor acúmulo foliar. Estes comportamentos foram encontrados pelos autores em estudo com densidade populacional de aproximadamente 158 
mil plantas por hectare. No presente trabalho utilizou-se população de plantas de cerca de 330 mil por hectare.

Observa-se comportamento diferenciado na análise de regressão para o teor de $\mathrm{P}$ foliar com o aumento da dose de $\mathrm{N}$ (Figura 2). Verificou-se um acréscimo no teor de $\mathrm{P}$ com doses de $\mathrm{N}$ maiores do que $100 \mathrm{~kg} \mathrm{ha}^{-1}$ (Figura 2A). Comportamento inverso pode ser verificado nas figuras 2B (HS) e 2C (PM), onde nota-se uma diminuição quadrática no teor de $\mathrm{P}$ com doses de $\mathrm{N}$ maiores de $100 \mathrm{~kg} \mathrm{ha}^{-1}$ e $50 \mathrm{~kg} \mathrm{ha}^{-1}$, respectivamente. Estes comportamentos podem estar relacionados com os manejos de irrigação, pois o manejo por PM (Figura 2C) foi o que aplicou menor quantidade de água $(246,6 \mathrm{~mm})$, o que pode ter resultado em menor absorção do nutriente. Os manejos por TCA (Figura 2A) e HS (Figura 2B) aplicaram maiores quantidades de água, 327,3 e 296,5 mm respectivamente, o que pode ter favorecido a absorção do $\mathrm{P}$ pela planta.
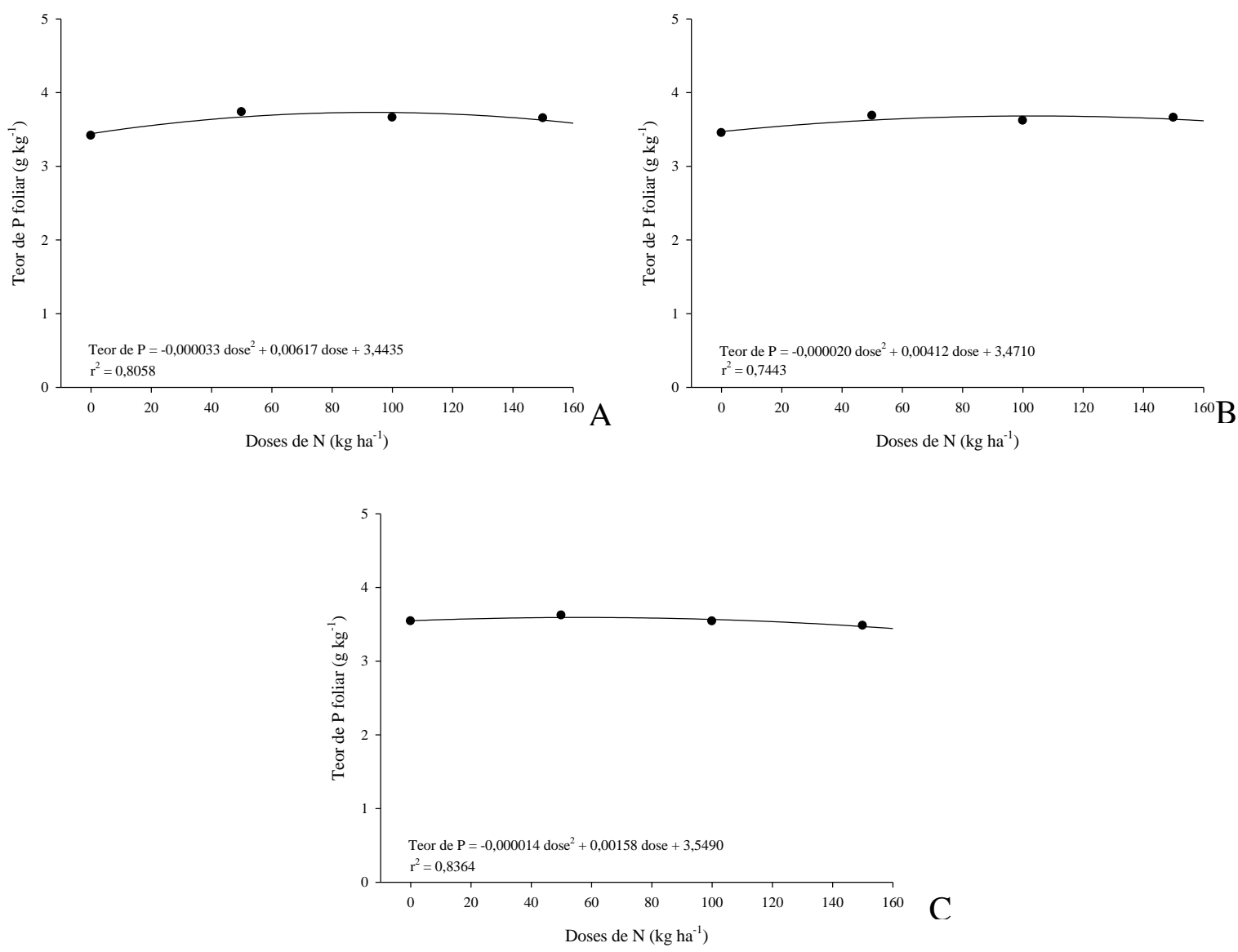

Figura 2. Teor de $\mathrm{P}$ foliar em diferentes doses de $\mathrm{N}$ na cultura do feijoeiro irrigado em sistema de plantio direto entre os manejos de irrigação: Tanque Classe A (A), Hargreaves-Samani (B) e Penman-Monteith (C), em Aquidauana - MS.

Resultado semelhante foi encontrado por Teixeira et al. (2008) na cultura do feijão no município de Lavras-MG, onde os teores de $\mathrm{P}$ foliar apresentaram uma redução até próximo a dose de $50 \mathrm{~kg} \mathrm{ha}^{-1}$, seguido de um aumento contínuo a partir desta dose. Segundo esses 
autores, o acréscimo no teor do elemento pode estar relacionado com o maior desenvolvimento das plantas, portanto, maior crescimento radicular, proporcionando aumento na absorção de $\mathrm{P}$, devido à exploração de um volume de solo maior.

Ainda segundo os autores, outra causa para o aumento nos teores do nutriente, pode ser devido à decomposição da palhada presente na área. Como não houve análise do sistema radicular nesse experimento, não se pode inferir que esse fator influenciou no comportamento verificado na Figura 2.

Segundo Silva et al. (2013), a absorção de nitrogênio na forma amoniacal diminui o pH da rizosfera, o que pode ter causado aumento na disponibilidade de $\mathrm{P}$, pois segundo Prado (2008), o pH é o que mais afeta a disponibilidade do $\mathrm{P}$ no solo, sendo valores próximos a 6,5 os que promovem maior disponibilidade no nutriente na solução do solo.

Verifica-se, nas Figuras 3A e 3B, que ocorre redução no teor de $\mathrm{B}$ até próximo à dose de $100 \mathrm{~kg} \mathrm{ha}^{-1}$ de $\mathrm{N}$, superior a essa dose ocorre um aumento nos teores do nutriente. Contudo, para a figura $3 \mathrm{C}$, ocorre um decréscimo independente da dose de $\mathrm{N}$ aplicada.
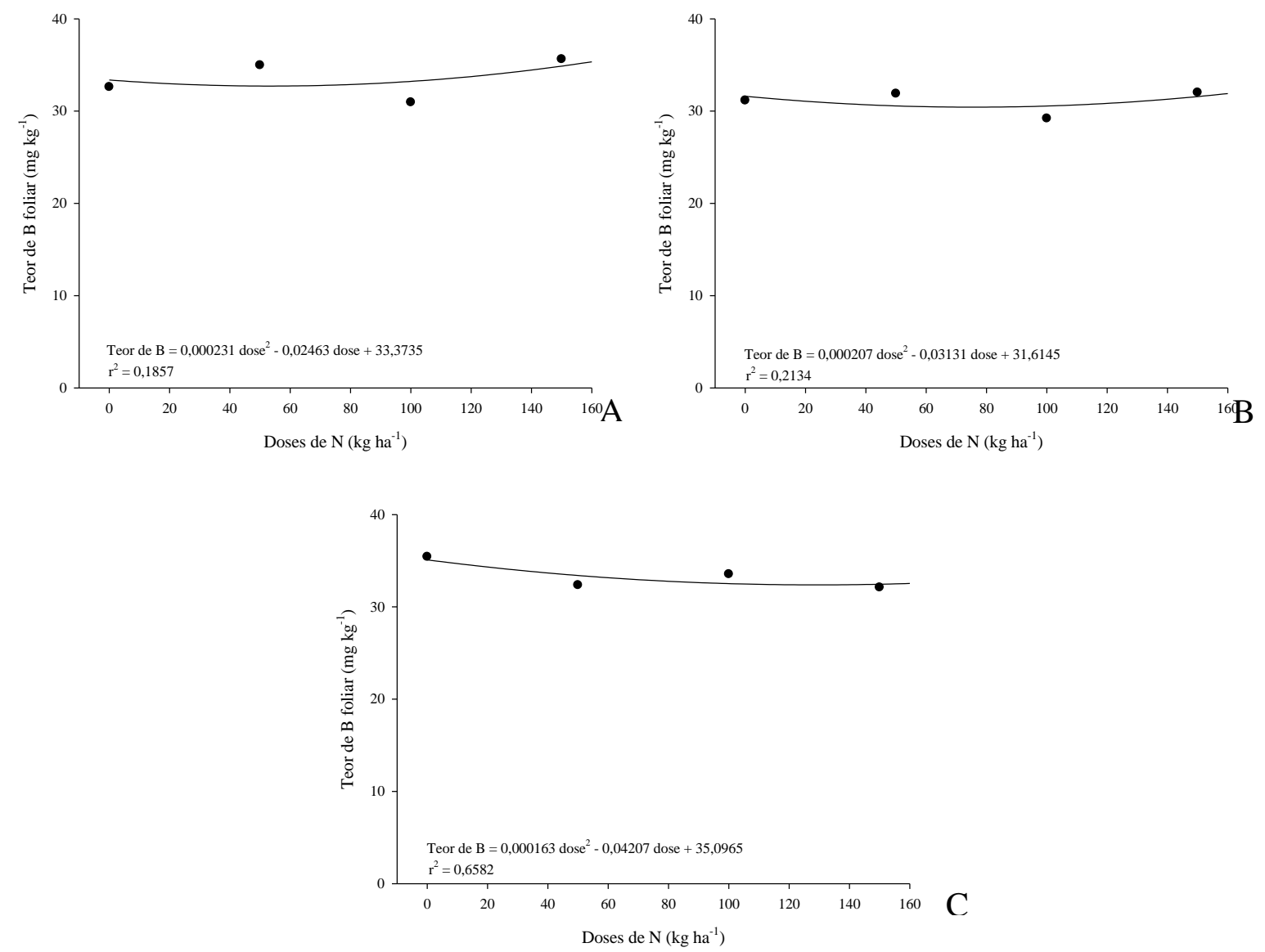

Figura 3. Teor de $\mathrm{B}$ foliar em diferentes doses de $\mathrm{N}$ na cultura do feijoeiro irrigado em sistema de plantio direto entre os manejos de irrigação: Tanque Classe A (A), Hargreaves-Samani (B) e Penman-Monteith (C), em Aquidauana - MS. 
Segundo Mascarenhas et al. (1998), altos valores de $\mathrm{pH}$ e baixas temperaturas, por a afetar a mineralização da matéria orgânica (uma das principais fontes de B), pode afetar negativamente a disponibilidade do $\mathrm{B}$ no solo. Visto que o experimento foi conduzido no período de inverno, onde as temperaturas são menores e o pH da área era de 5,8 (Tabela 1), próximo ao encontrado pelos autores que foi de 6,3 , pode ter causado menor disponibilidade do nutriente no solo e, segundo Silva et al. (2013), a aplicação de N quando os níveis de B no solo são baixos, pode induzir a deficiência do B em decorrência da menor absorção do mesmo.

Entretanto, doses mais elevadas de $\mathrm{N}$ podem causar redução do $\mathrm{pH}$ próximo as raízes, pois a absorção de nitrogênio na forma amoniacal diminui o $\mathrm{pH}$ da rizosfera (SILVA et al., 2013), afetando positivamente a mineralização da matéria orgânica, resultando em maior disponibilidade do nutriente, causando maior acúmulo foliar em função dessa absorção de B.

\section{CONCLUSÃO}

As maiores produtividades do feijoeiro não estão relacionadas com os maiores teores foliares de N, P e B.

A aplicação de elevadas doses de $\mathrm{N}$ e o manejo de irrigação não acarretam em maiores acúmulos de N, P e B foliar na cultura do feijão, em Aquidauana-MS.

\section{REFERÊNCIAS BIBLIOGRÁFICAS}

ALLEN, R. G.; PEREIRA, L. S.; RAES, D.; SMITH, M. Pan evaporation method. In: Crop evapotranspiration: guidelines for computing crop requirements. Roma: FAO, 1998. p. 7885.

AMBROSANO, E. J.; TANAKA, R. T.; MASCARENHAS, H. A. A.; RAIJ, B. van; QUAGGIO, J. A.; CANTARELLA, H. Leguminosas e oleaginosas. In: RAIJ, B. van; CANTAELlA, H.; QUAGGIO, J. A.; FURLANI, A. M. C. Recomendações de adubação e calagem para o estado de São Paulo. 2. ed. Instituto Agronômico, 1996. p. 187-203.

ARAÚJO, E. O.; CAMACHO, M. A. Interação boro e zinco no crescimento, desenvolvimento e nutrição do algodoeiro. Revista Brasileira de Ciências Agrárias, Recife, v. 7, suppl., p.720-727, 2012.

ARF, M. V.; BUZETTI. S; ARF, O.; KAPPES, C.; FERREIRA, J. P.; GITTI, D. C.; YAMAMOTO, C. J. T. Fontes e épocas de aplicação de nitrogênio em feijoeiro de inverno sob sistema plantio direto. Pesquisa Agropecuária Tropical, Goiânia, v. 41, n. 3, p.430-438, 2011.

BANZATTO, D. A.; KRONKA, S. N. Experimentação Agrícola. FUNEP, 1989. 247 p. CONAB - COMPANHIA NACIONAL DE ABASTECIMENTO. Acompanhamento da safra brasileira. Grãos - Safra 2016/17, Terceiro levantamento, 2016. 156 p.

Cultura Agronômica, Ilha Solteira, v.26, n.1, p.21-32, 2017 
CRUSCIOL, C. A. C.; SORATTO, R. P.; SILVA, L. M.; LEMOS, L. B. Fontes e doses de nitrogênio para o feijoeiro em sucessão a gramíneas no sistema plantio direto. Revista Brasileira de Ciência do Solo, Viçosa, v. 31, n. 6, p.1545-1552, 2007.

CUNHA, P. C. R; SILVEIRA, P. M.; XIMENES, P. A.; SOUSA, R. F.; ALVES JÚNIOR, J.; NASCIMENTO, J. L. Fontes, formas de aplicação e doses de nitrogênio em feijoeiro irrigado sob plantio direto. Pesquisa Agropecuária Tropical, Goiânia, v. 41, n. 1, p.80-86, 2011.

EMBRAPA - Empresa Brasileira de Pesquisa Agropecuária. Manual de análises química de solos, plantas e fertilizantes. 2. ed. rev. ampl. Brasília: Embrapa Informação Tecnológica, 2009. $627 \mathrm{p}$.

LOPES, A. S.; OLIVEIRA, G. Q.; SOUTO FILHO, S. N.; GOES, R. J.; CAMACHO, M. A. Manejo de irrigação e nitrogênio no feijoeiro comum cultivado em sistema plantio direto. Revista Ciência Agronômica, Fortaleza, v. 42, n. 1, p.51-56, 2011.

MALAVOLTA, E.; LIMA FILHO, O. F. Nutrição e adubação do feijoeiro. In: FANCELLI, A. L.; DOURADO-NETO, D. Tecnologia da produção de feijão irrigado. Piracicaba: ESALQ, 1997. p. 22-51.

MASCARENHAS, H. A. A.; TANAKA, R. T.; NOGUEIRA, S. S. S.; CARMELLO, Q. C.; AMBROSANO, E. J. Resposta do feijoeiro a doses de boro em cultivo de inverno e de primavera. Bragantia, Campinas, v. 57, n. 2, p.267-269, 1998.

PACHECO, A.; OLIVEIRA, G. Q. O.; LOPES, A. S.; BARBOSA, A. S. Manejos de irrigação e nitrogênio na produção de feijoeiro. Pesquisa Agropecuária Tropical, Goiânia, v. 42, n. 3 , p.323-330, 2012.

PAVANI, L. C.; LOPES, A. S.; PEREIRA, G. T. Desenvolvimento da cultura do feijoeiro submetida a dois sistemas de manejo de irrigação e de cultivo. Acta Scientiarum Agronomy, Maringá, v. 31, n. 3, p.453-459, 2009.

PELEGRIN, R.; MERCANTE, F. M.; OTSUBO, I. M. N.; OTSUBO, A. A. Resposta da cultura do feijoeiro à adubação nitrogenada e à inoculação com rizóbio. Revista Brasileira de Ciência do Solo, Viçosa, v. 33, n. 1, p.219-226, 2009.

PEREIRA, A. R.; VILLA NOVA, N. A.; SEDIYAMA, G. C. Evapotranspiração. Piracicaba: FEALQ, 1997. 183 p.

PRADO, R. M. Nutrição de plantas. São Paulo: UNESP, 2008. 407 p.

PROCÓPIO, S. O.; SANTOS, J. B.; PIRES, F. R.; SILVA, A. A.; MENDONÇA, E. S. Absorção e utilização do fósforo pelas culturas da soja e do feijão e por plantas daninhas. Revista Brasileira de Ciência do Solo, Viçosa, v. 29, n. 6, p.911-921, 2005.

ROQUE, M. W.; MATSURA, E. E.; Aline, R. P.; RAMOS, F. T. Correlação da variabilidade espacial entre a produtividade do feijoeiro irrigado e a densidade do solo. Global Science and Technology, Rio Verde, v. 3, n. 3, p.22-30, 2010. 
SCHIAVO, J. A.; PEREIRA, M. G.; MIRANDA, L. P. M.; DIAS NETO, A. H.; FONTANA, A. Caracterização e classificação de solos desenvolvidos de arenitos da formação Aquidauana- MS. Revista Brasileira de Ciência do Solo, Viçosa, v. 34, n. 3, p.881-889, 2010.

SILVA, I. P.; SILVA, J. T. A.; CARVALHO, J. G. Nitrogênio e boro em mudas de bananeira Prata Anã cultivadas em casa de vegetação. Revista Agrarian, Dourados, v. 6, n. 19, p.5159, 2013.

SILVA, J. I. C.; FERNANDES, D. M.; PEREIRA, M. R. R.; LELES, E. P.; PEREIRA, F. R. S; CRUZ, S. C. S. Interferência do hipoclorito de sódio na absorção de macro e micronutrientes nas culturas da soja e do feijão. Bioscience Journal, Uberlândia, v. 26, n. 2, p.257-265, 2010.

SORATTO, R. P.; CARVALHO, M. A. C.; ARF, O. Teor de clorofila e produtividade do feijoeiro em razão da adubação nitrogenada. Pesquisa Agropecuária Brasileira, Brasília, v. 39, n. 9, p.895-901, 2004.

TEIXEIRA, C. M.; CARVALHO, G. J.; FURTINI NETO, A. E.; ANDRADE, M. J. B.; FONTANETE, A. Produtividade e teores foliares de nutrientes do feijoeiro sob diferentes palhadas e doses de nitrogênio em semeadura direta. Acta Scientiarum Agronomy, Maringá, v. 30. n. 1. p.123-130, 2008.

ZUCOlOTO, M.; LIMA, J. S. S.; COELHO, R. I.; SILVA, S. A.; SOUZA, G. S. Estiva de $\mathrm{Ca}$ e $\mathrm{Mg}$ foliares por meio de $\mathrm{Ca}$ e $\mathrm{Mg}$ do solo em bananeira prata anã utilizando cokrigagem. Bioscience Journal, Uberlândia, v. 26, n. 6, p.835-842, 2010. 